\title{
A TRAJETÓRIA DO MOVIMENTO DAS MULHERES TRABALHADORAS RURAIS DO SERTÃO CENTRAL DE PERNAMBUCO: 1984 - 2015
}

\author{
Cristiana Rodrigues Carvalho ${ }^{1}$ \\ Maria Aparecida Tenório Salvador Costa
}

\section{RESUMO}

O artigo apresenta uma análise da trajetória de mobilização, engajamento e articulação das mulheres agricultoras rurais que resultou no Movimento das Mulheres Trabalhadoras Rurais do Sertão Central/PE. Ao longo de mais de 30 anos de luta, ele desenvolveu estratégias de comunicação diferenciadas ao mesmo tempo em que (re)construiu discursos e posicionamentos que possibilitaram uma maior autonomia, visibilidade e empoderamento às trabalhadoras rurais. Os dados foram coletados mediante análise documental, observação e entrevista semiestruturada. $E$ a de análise foi feita a partir da Análise do Discurso. Buscou-se ligar o campo conceitual ao universo no qual as trabalhadoras estão inseridas, evidenciando assim seus códigos, crenças e linguagens, que normalmente se apresentam estruturadas em uma forma de vida particular e diferenciada, sustentada pela base de uma agricultura familiar. $O$ resultado permitiu uma compreensão maior dos elementos que foram determinantes para que as mulheres tivessem coragem de combater as dificuldades que as excluíam das questões sociais, ao mesmo tempo em que sentiam uma maior necessidade e urgência de se reunir e se organizar enquanto movimento social.

Palavras-chaves: desenvolvimento local, discurso, movimento social de mulheres rurais.

\section{THE TRAJECTORY OF THE RURAL WORKERS WOMEN'S MOVEMENT OF THE HINTERLAND OF CENTRAL PERNAMBUCO: 1984-2015}

\begin{abstract}
This paper presents an analysis of the mobilization trajectory, engagement and articulation of women farmers that led to the setting up of the Movement of Women Farmers of the Sertão Central/PE. Following a 30-year struggle, it has developed specific communication strategies to re(construct) discourses and stances which have provided women farmers with a greater autonomy, visibility and empowerment.

${ }^{1}$ Graduada em Comunicação Social (UNICAP). Especialização em Gestão Pública; Formação Política e Administração do Legislativo (UPE). Mestrado em Extensão Rural (UFRPE). E-mail: crizrodrigues8@gmail.com.br.

${ }^{2}$ Graduada em Pedagogia (FACHO). Mestrado em Educação (UFPE). Doutorado Sociologia (UFPE). Professora do Departamento de Educação da Universidade Federal Rural de Pernambuco (UFRPE) e do Programa de Pós-Graduação em Extensão Rural e Desenvolvimento Local (UFRPE). E-mail: aparecidatcosta@hotmail.com.br.
\end{abstract}


All data has been collected by means of documentary analyses, direct observation and semi-structured interviews. The analysis as ben based on the Speech Analysis. The objective was to connect the conceptual field the universe in which the rural workers lead their lives evidencing their codes, beliefs and languages, which were usually presented in a particular and distinctive way of live. Based on familiar farming. The results provided a better understanding of the determinants essential for women to have the courage to fight the difficulties that have been keeping them excluded from social issues and, at the same time, provided them with the feeling of urgency to get together and organize themselves in a social movement.

Keywords: local development, social movement of rural women, speech.

\section{CRIAÇÃO, MOBILIZAÇÃO E ENGAJAMENTO DAS TRABALHADORAS RURAIS}

A vida das mulheres trabalhadoras rurais do Sertão Central do estado de Pernambuco é marcada por uma história de muitas lutas e algumas conquistas. Elas nasceram e cresceram em uma sociedade patriarcal, cercadas por diversos tipos de violência e desigualdades, onde as relações sociais vigentes favoreciam o poder do mais forte, ou seja, dos homens. Os discursos defendidos nessa região por padres, políticos, donos de terras, esposos e filhos, não valorizavam a participação e a opinião das mulheres, inicialmente em casa e em seguida nos espaços sociais. Assim, entendia-se a mulher, dentro e fora de casa, como submissa, mesmo que ainda dividissem as tarefas na roça ou no trato com os animais, acumulando mais funções que os homens.

Antes da década de 80 do século XX, essas mulheres trabalhadoras rurais e sertanejas integravam os sindicatos apenas como dependentes de seus pais e maridos. Havia na sociedade daquela época uma compreensão de que esse trabalho da mulher era complementar, uma simples ajuda aos chefes de família, consequentemente não havia remuneração por seu desempenho e tampouco o reconhecimento de sua contribuição como trabalhadora rural. A produção na roça, na maioria dos sítios, destinava-se ao sustento da própria família e o pouco dinheiro arrecadado era aplicado na aquisição de itens do consumo familiar, como roupas, sapatos, utensílio para o lar, produtos alimentícios industrializados e instrumentos de trabalho.

Mesmo diante dessa realidade, surge um pequeno grupo de mulheres, da citada região, que inicia um longo percurso para enfrentar e romper com os padrões sociais dessa época. As mulheres que trabalhavam na agricultura familiar começaram a se reunir, discutir seus interesses, organizar seus discursos a partir da troca de experiências entre elas e outros sujeitos, criando novas relações sociais que influenciaram na comunidade e no desenvolvimento local. Elas realizaram as primeiras articulações que contribuíram para o surgimento de um movimento liderado por trabalhadoras rurais, conferindo a esses sujeitos visibilidade e autonomia. Assim, nascia em 1984 o Movimento das Mulheres Trabalhadoras Rurais do Sertão Central de Pernambuco - MMTR - Sertão Central - PE.

Com essa articulação, as agricultoras passaram a se posicionar como trabalhadoras rurais e a participar das instâncias de tomadas de decisões que influenciavam suas vidas, tanto na esfera particular quanto coletiva, lutando por seus direitos e criando uma organização pautada em legítimas reivindicações. A trajetória dessas agricultoras, destacadamente suas lutas e conquistas, tornou-se foco de interesse da pesquisa que resultou neste artigo. Desse modo, o estudo buscou 
compreender os elementos que foram determinantes para que as mulheres tivessem coragem de combater as dificuldades que as excluíam das questões sociais, que rebatiam nas suas vidas, ao mesmo tempo em que sentiam uma maior necessidade e urgência de se reunir e se organizar enquanto movimento social.

A forte seca que assolou o sertão pernambucano, entre os anos de 1979 a 1984 teria impulsionado uma maior organização dessas mulheres, pois muitas delas passariam nesse período de estiagem, à condição de chefes de família. Essa situação de liderança era assumida pela ausência de seus maridos, que sem oportunidade de trabalho, migravam para outras regiões do estado ou do país. Abreu e Lima (2012) aponta o alistamento feminino nas Frentes de Emergência no Departamento Nacional de Obras Contra a Seca (DNOCS) como uma bandeira de luta concreta, que despertaria definitivamente nas mulheres uma atenção especial para a necessidade e urgência da criação de um movimento liderado pelas trabalhadoras rurais.

O estudo teve como objetivo geral, analisar a trajetória do Movimento das Mulheres Trabalhadoras Rurais do Sertão Central de Pernambuco - MMTR - Sertão Central - PE, a partir da análise dos discursos desses sujeitos sociais. Seus objetivos específicos foram: reconhecer as estratégias de comunicação utilizadas pelo MMTR - Sertão Central - PE para mobilização e organização das mulheres agricultoras por meio dos seus discursos, bem como compreender as contribuições que o MMTR - Sertão Central - PE proporcionou à vida das mulheres agricultoras e ao desenvolvimento local.

Ao longo de mais de 30 anos de luta, o Movimento desenvolveu estratégias de comunicação diferenciadas ao mesmo tempo em que (re) construiu discursos e posicionamentos que permitiram uma maior autonomia, visibilidade e empoderamento às trabalhadoras rurais, transformando as relações sociais ao longo da trajetória do grupo e influenciando a comunidade as comunidades rurais.

As primeiras abordagens junto a essas trabalhadoras foram organizadas por uma das moradoras da região, Vanete Almeida $^{3}$, que ficava incomodada com a ausência das mulheres nas reuniões dos sindicatos dos trabalhadores rurais, e quando o encontro acontecia na casa de uma delas, sequer chegavam ao ambiente em que o grupo estava reunido. E, essa moradora, saía à procura das mulheres do campo para conversar sobre a seca, sobre como gostariam que fossem suas vidas, sobre a sua não participação nas reuniões nos sindicatos e, até mesmo, nas reuniões realizadas em suas casas (ALMEIDA, 1995, p. 116).

Em muitos casos, participar de sindicato, nos anos 70 e 80 , era visto como um risco moral para as mulheres, mesmo na condição de funcionária. Para Abreu e Lima (2012), este tipo de discriminação é outro elemento que explica a pequena presença da mulher nesses espaços. Nas suas pesquisas, a autora constata que a participação das mulheres fazia com que elas ficassem "faladas" e no âmbito familiar, sofressem pressões muito fortes até porque a questão envolvia o aspecto emocional, afetivo, a honra e o nome da família.

\footnotetext{
${ }^{3}$ Vanete Almeida não era trabalhadora rural. No fim da década de 1970 e início de 1980, atuava junto aos setores da Igreja Católica. Conhecida como liderança local, foi convidada por Euclides Nascimento, então presidente da FETAPE para realizar um trabalho de organização sindical na região tornando-se assessora da Federação no Polo Sertão Central e assim percebeu a ausência feminina nos sindicatos.
} 


\section{MÉTODO DE APROXIMAÇÃO DO UNIVERSO RURAL}

O universo da pesquisa foi o município de Serra Talhada, em Pernambuco, local onde foram realizadas as primeiras reuniões com as trabalhadoras rurais e onde está situada a sede do Polo Sindical do Sertão Central. Também foram realizadas visitas à Federação dos Trabalhadores na Agricultura do Estado de Pernambuco (FETAPE) para coleta de informações extraídas dos documentos dessa instituição, como também os materiais impressos produzidos pelas agricultoras ${ }^{4}$.

Os sujeitos da pesquisa compuseram um grupo de agricultoras que fundaram o Movimento das Mulheres Trabalhadoras Rurais do Sertão Central de Pernambuco; agricultoras que deram/dão continuidade ao movimento; e lideranças sindicais que integram a luta pelos direitos das mulheres do campo. Desta maneira, foram entrevistadas seis trabalhadoras rurais moradoras das cidades que compõem o Sertão Central: Custódia, Caiçarinha da Penha, Serra Talhada, Triunfo e São José do Belmonte. Essas mulheres ocupam cargos de presidência e diretoria dos Sindicatos dos Trabalhadores Rurais das regiões citadas e compõem a coordenação do MMTR Sertão Central. Três das entrevistadas acompanharam o movimento desde seu surgimento, e relataram todo o início das articulações junto às trabalhadoras rurais. As outras três entrevistadas ingressaram na organização depois da década de 1990, e ocuparam cargos de liderança. Ainda foram ouvidas duas jovens trabalhadoras rurais que revelaram em seus discursos os momentos de crescimento do grupo. As entrevistas - individuais e semiestruturadas - foram gravadas, em áudio e vídeo e não seguiram um roteiro. Foram recolhidos depoimentos sobre a trajetória de vida de cada agricultora, sua relação e aprendizado no meio rural, o envolvimento com o movimento e as contribuições para a luta das trabalhadoras rurais.

Com o intuito de ampliar os discursos e comparar ao que era dito naquela época em que o MMTR - Sertão Central - PE surgiu, foram apreendidos do material documental $^{5}$, os pronunciamentos, as falas e posicionamentos dos trabalhadores rurais. Na primeira década do Movimento, apenas alguns homens que já estavam à frente dos sindicatos e instituições, apoiavam o Movimento das mulheres rurais. Eles revelaram seu reconhecimento ao movimento e à crescente participação da mulher. Já no começo da segunda década, se inicia um processo de aproximação dos agricultores nas reuniões e encontros organizados pelas mulheres e assim, os discursos começam a mudar e os homens do campo passam a contribuir com suas opiniões.

A pesquisa também buscou identificar os discursos proferidos durante a trajetória do movimento, construídos pelas organizações e instituições parceiras. A primeira reunião, em dezembro de 1982, congregou apenas 14 mulheres, oriundas de cinco comunidades rurais. Nessa primeira discussão, as agricultoras apontaram diversas dificuldades como a falta de oportunidade nas Frentes de Emergência, a escassez de água e os preços caros dos produtos. Em janeiro de 1983, o grupo realizou novo encontro reunindo 11 mulheres de 04 comunidades, ainda abordando os mesmos assuntos e buscando juntas, alternativas. Nos meses de março e junho, deste mesmo ano, 42 trabalhadoras rurais, de 07 comunidades, se reuniram propondo alternativas às problemáticas da época. Foram elencados 20 itens, entre eles: necessidade dos homens trabalharem na roça mesmo no período da seca,

\footnotetext{
${ }^{4}$ Cartilha, folder, carta aberta e relatórios dos encontros anuais no período de 1984 a 2009.

${ }^{5}$ Relatórios do acervo do Movimento de Mulheres Trabalhadoras Rurais, desde a década de 80 até a de 2000 , totalizando oito relatórios.
} 
salário emergência baixo, participação da mulher na luta sindical e a proposta de realizar um encontro com as mulheres na cidade pernambucana de Serra Talhada. Nos meses de novembro e dezembro de 1984, os encontros voltam a acontecer e as agricultoras traçam o planejamento para o primeiro Encontro das Mulheres Trabalhadoras Rurais do Sertão Central de Pernambuco.

Para a análise das informações acolhidas dos documentos e falas dos sujeitos pesquisados recorreu-se à Análise do Discurso - $A D$, visando a compreensão de como um objeto simbólico produz sentido, como está investido na significância para si e para os outros sujeitos envolvidos. Introduzida por Pêcheux (1969), a Análise de Discurso é aquela na qual a linguagem é estudada não apenas enquanto forma linguística, mas também como forma material da ideologia.

Assim, este estudo considerou em suas análises não somente o que é dito em determinado momento, mas as relações que esse dito estabelece com o que já foi dito e, até mesmo, com o não dito, atentando, também para as posições social e histórica dos sujeitos envolvidos, assim como para as formações discursivas às quais se filiam os discursos.

Segundo Orlandi (2005), é pela análise do discurso que se pode refletir sobre as relações significativas fundamentais entre o homem, a natureza e a sociedade na história.

Pelo discurso, lugar de produção de sentidos e de processo de identificação dos sujeitos, podemos melhor compreender o lugar de interpretação na relação do homem com a sua realidade. Por este tipo de estudo se pode conceber melhor aquilo que faz o homem um ser especial com sua capacidade de significar e significar-se (ORLANDI, 1995, p.15).

Os discursos dos sujeitos, extraídos dos documentos e das entrevistas, foram categorizados de acordo com a posição social que esses sujeitos ocuparam/ocupam no MTTR - Sertão Central - PE, ao longo do tempo recortado para esse estudo. Foram as seguintes as categorias de análise: os discursos das mulheres agricultoras rurais; os discursos dos homens agricultores rurais; os discursos das instituições sindicais e outras organizações.

Os sujeitos receberam a seguinte codificação: na primeira categoria, três discursos das mulheres fundadoras do Movimento, MF1, MF2 e MF3; três discursos das lideranças do Movimento - ML1, ML2 e ML3; e dois discursos das jovens mulheres trabalhadoras rurais - JM1 e JM2. A categoria seguinte revela os discursos dos homens agricultores rurais, que envolvem três falas dos sujeitos que presenciaram o surgimento do Movimento, $\mathrm{H} 1, \mathrm{H} 2$ e H3; e ainda de dois homens na atualidade do Movimento - HA1, HA2. A terceira categoria ressalta os discursos das instituições sindicais e outras organizações, reunidos em dois depoimentos: I1, I2.

A partir da pesquisa exploratória, foi possível encontrar uma vasta literatura acerca dos movimentos sociais protagonizados por mulheres agricultoras rurais, e encontrou inúmeros trabalhos acerca da temática, desenvolvidos local e nacionalmente. No âmbito local diversos trabalhos sobre as mulheres agricultoras rurais do estado de Pernambuco foram encontrados, enfocando: Identidade (JALIL, 2013; CORDEIRO, 2007); Gênero (SILIPRANDI; CINTRÃO, 2009; LUCENA, 2002); Educação (SANTANA, 2014; CARVALHO, 2004); Trabalho (MILANÊS, 2015; DUARTE, 2009); Movimentos Sociais (BARDALO, 2013; SOUZA, 2010; HEREDIA; CINTRÃO, 2006; VIEIRA; SANTOS, 2014), entre outros. Dentre eles, pode-se destacar a dissertação de Siqueira (2015) que buscou analisar as representações sociais das mulheres rurais sobre os saberes construídos a partir da sua inserção 
nos movimentos sociais, localizados no município de Afogados da Ingazeira - PE. E, a tese de Jalil (2013), que apresentou uma reflexão sobre o Movimento de Mulheres Trabalhadoras Rurais do Sertão Central de Pernambuco como um novo sujeito político que reconfigura o mundo rural a partir das demandas e questionamentos específicos apresentados pelas mulheres rurais, como forma de ação coletiva.

Entre as produções nacionais, vários são os estudos que se preocuparam em investigar aspectos relacionados às mulheres trabalhadoras rurais, como os aspectos políticos, culturais, econômicos, sociais, etc. Do conjunto desses trabalhos pode-se citar o de Salvaro, Lago e Wolf (2013), que se ocupou do estudo sobre identidades políticas que carregam as expressões "mulheres agricultoras" e "mulheres camponesas", a partir de um movimento rural de mulheres no período de 2006-2010, no estado de Santa Catarina. E o estudo de Silva (2007) que tem como foco a análise do papel socializador do Movimento do Nordeste Paraense, cuja pesquisa foi realizada no biênio 2007-2008. Trata-se de um estudo empírico de natureza qualitativa que busca analisar o Movimento de Mulheres do Nordeste Paraense enquanto movimento social e regional e seu papel de agência socializante, considerando: os processos responsáveis pela socialização de mulheres agricultoras nele inseridas; a influências que as mulheres têm na socialização umas das outras e em que aspectos isso se reflete na continuidade do Movimento; como o Movimento socializa os homens ali inseridos e como estes homens influenciam a socialização das mulheres no Movimento. No artigo em Extensão Rural, de Silva e Lima (2016), encontra-se referência a mobilização das trabalhadoras rurais, na década de 1980, que objetivava direitos referentes à previdência social - aposentadoria, salário maternidade, entre outros. E, segundo os autores, à medida que iam ocorrendo os avanços desses movimentos, possibilitavase o reconhecimento da profissão de trabalhadoras rurais.

Nota-se dessa maneira que os estudos encontrados contribuíram para a tomada de decisão acerca do objeto de pesquisa, possibilitando a construção do marco teórico que fundamenta este trabalho. Assim, analisar a trajetória do Movimento das Mulheres Trabalhadoras Rurais - MMTR implicou também em aprofundar conceitos como Movimentos Sociais, Comunicação nos Movimentos Sociais e Desenvolvimento Local, que de variadas maneiras foram também encontrados na maior parte dos trabalhos revisados.

\section{O DISCURSO DAS TRABALHADORAS RURAIS ATRAVÉS DOS TEMPOS}

Conhecer o caminho trilhado pelas trabalhadoras rurais do sertão pernambucano através de seus discursos simplicou e valorizou as vozes desses sujeitos sociais, que se apresentaram ricas de significados. Os discursos trouxeram à tona discussões sobre a posição social, reconhecimento e valorização da mulher. Perceber as ações que estimularam a mobilização e engajamento, enquanto movimento social, fez com que o sentido da ação conjunta fosse materializado, justamente porque essas agricultoras saíram do anonimato e passaram à condição de protagonistas. Uma época difícil, com escassez de recursos, e que revelou a importância que essa articulação trouxe, ou seja, um despertar que gerou transformações no desenvolvimento das comunidades rurais da região estudada e, especialmente transformações nas vidas das mulheres rurais brasileiras.

Entende-se, no meio rural, que há uma tensão muito forte em relação ao protagonismo da mulher. Para Jalil (2013), a liderança das trabalhadoras rurais está diretamente relacionada à manutenção da unidade produtiva, obedecendo a um tripé família - produção - trabalho. "Assim, para as mulheres rurais, a construção da 
identidade de trabalhadora rural passa pelo reconhecimento da importância do seu papel como reprodutora da família e como produtora de bens e valores simbólicos e culturais" (JALIL, 2013, p.49).

O sujeito, enquanto produto de relações sociais, não é livre de coerções. Ele aprende a ver o mundo, adquire crenças e conhecimentos por meio dos discursos - que exprimem ideologias - que assimilam e reproduzem a partir de um lugar. Ao participarem da pesquisa, as mulheres rurais expressaram sua forma de compreender o mundo revelando uma formação discursiva e uma formação ideológica, baseadas nos seus saberes, nas suas crenças, nas suas experiências. Enquanto a formação ideológica impõe o modo de pensar e compreender o mundo, a formação discursiva impõe o que dizer. A criação de regiões de sentidos é função do discurso e, em última análise, é o discurso que servirá de suporte e determinação de identidade tanto para o sujeito discursivo quanto para a sociedade onde ele é produzido (ORLANDI, 1995).

No processo de análise das informações acessadas nos documentos e nas falas dos sujeitos pesquisados, foi possível perceber a posição de destaque que o "silêncio" ocupou na vida das mulheres rurais participantes da investigação. Os discursos "não ditos" podem ser entendidos como os diversos significantes que ao se unirem possibilitam perceber o sentido. A ausência do discurso explícito pode significar ao interlocutor a compreensão de que resposta alguma também é uma resposta, e sendo assim, é composta de relações de possibilidades significantes. Dessa forma, a pesquisa permitiu entender, que o silêncio, típico no ambiente das trabalhadoras rurais, criou uma relação com os sujeitos revelando que a sua invisibilidade determinou as condições de submissão e inferioridade das mulheres estudadas na região e no tempo já referido.

Os títulos dos relatórios produzidos pelo MMTR - Sertão Central - PE demonstram o esforço em romper com o que era dito pelo dominador, ou seja, o homem. São alguns desses títulos: "O que sentem e o que querem as mulheres trabalhadoras rurais do Sertão" (1984); "Quem sou eu?" (1986); "Quem somos nós?" (1986); "Por que os ricos sendo tão poucos dominam os pobres" (1986); e, ainda, os trabalhos desenvolvidos com temas inter-relacionados como: Corpo $X$ Destino (1986); Afetividade X Sexualidade (1992); Relação de poder entre mulheres (1993); Relações de gênero (1995). Esses temas, desdobrados em debates e diversas produções, marcam a ruptura com o discurso hegemônico e o silêncio das mulheres.

\footnotetext{
O silêncio é assim a respiração - o fôlego - da significação, um lugar de recuo necessário para que se possa significar, para que o sentido faça sentido. Reduto do possível, do múltiplo, o silêncio abre espaço para o que não é um, para o que permite o movimento do sujeito (ORLANDI, 2011, p.13).
}

Assim, a década de 1980 trouxe uma chance para que as mulheres do campo iniciassem seu processo de expressão, contribuindo para a criação e articulação de um movimento social crescente, em busca do reconhecimento e valorização da participação das mulheres no meio rural na sociedade. Um movimento que estava baseado na ideia de conflitos e transformações sociais, considerando o tipo de ação coletiva que emergiu de uma insatisfação grupal. Siliprandi e Cintrão (2009) ressaltaram a importância desta trajetória de engajamento das trabalhadoras rurais na conquista de seus direitos civis, o que permitiu avanços, ao mesmo tempo em que colocaram em pauta novos desafios a serem enfrentados. O discurso sempre se constrói a partir de uma totalidade histórica, na qual são produzidas as representações do mundo, reunindo as espécies de crenças e de 
conhecimentos. É possível, então, perceber que o MMTR - Sertão Central-PE trouxe contribuições para o desenvolvimento local, na medida em que a construção de coletivos de agricultores/as possibilitou a esses sujeitos sociais se reconhecerem como capazes de discutir suas questões e decidir os encaminhamentos que beneficiassem efetivamente as pessoas das diversas localidades que integravam o Movimento. Como explica Jesus (2003, p.72): "o desenvolvimento local pode ser entendido como um processo que mobiliza pessoas e instituições buscando informações da economia e da sociedade locais, criando oportunidades de trabalho e de renda".

$\mathrm{Na}$ categoria das mulheres agricultoras rurais foram agrupados os discursos das trabalhadoras que participaram diretamente do Movimento de Mulheres, desde a sua origem, em 1984 até o período de desenvolvimento deste trabalho, 2015. Contudo, esta categoria reclama uma subdivisão, ou seja: os discursos das fundadoras da organização, que tinham em seus argumentos, os elementos motivacionais e encorajadores, que iniciaram o processo de mobilização da organização; os discursos das agricultoras que se destacaram e ocuparam posições de liderança e que utilizaram estratégias de comunicação para estimular a participação das mulheres do campo; e os discursos das jovens trabalhadoras que aderiram ao grupo, após a segunda metade da década de 1990 e início dos anos 2000, revelando e comunicando as contribuições que o MMTR - Sertão Central-PE proporcionou à vida do grupo.

Estas mulheres agricultoras nasceram em um universo rural, com base em uma agricultura do campo, tecendo assim, um modo econômico, social, político e cultural que se produziu e se produz na relação com os agentes sociais. Estabeleceram especificidades que lhes é própria, seja em relação ao modo de produzir e à vida comunitária, seja na forma de convivência com a seca. Os camponeses que não aceitaram os processos de exploração econômica e dominações políticas de classes dominantes capitalistas construíram, de certa forma, uma identidade destinada à resistência (CALDART, 2012).

Os discursos das mulheres fundadoras do Movimento foram ricos de argumentos encorajadores, um movimento radical que transformou a forma como as agricultoras pensavam, buscavam informações e se expressavam. Ao mudar de discurso, as palavras também começaram a mudar de sentido e neste aspecto nasceu um novo comportamento entre as mulheres trabalhadoras rurais.

Para Foucault (2005) interessa sempre indicar que o discurso, tido como verdadeiro, é portador de poder. E este é concebido como luta. Para ele, o poder não possui uma identidade própria, unitária e transcendente, mas está distribuído em toda a estrutura social e é sempre socialmente produzido.

A perspectiva história aborda as relações entre poder, saber e subjetivação, que perpassam pela constituição do sujeito, revelando em seu estudo que a língua, o corpo e a cidade são marcados por exercícios de poder próprios à sociedade atual, compreendida, em termos "foucaultianos", como uma sociedade que se pode controlar.

A construção do ideológico pode ser sintetizada a partir da seguinte forma: "a verdade está circularmente ligada a sistemas de poder, que a produzem e a apoiam e a efeitos de poder que ela induz e a reproduzem" (FOUCAULT, 1980, p. 131). Para o autor, existe uma relação entre verdade e poder, e todos os discursos podem ser vistos funcionando em regimes de verdade.

Cada sociedade tem seu regime de verdade, sua política geral de verdade: isto é, os tipos de discurso que aceita e faz funcionar como verdadeiros, os mecanismos e instâncias que 
permitem distinguir entre sentenças verdadeiras e falsas, os meios pelos quais cada um deles é sancionado; as técnicas e procedimentos valorizados na aquisição da verdade; o status daqueles que estão encarregados de dizer o que conta como verdadeiro (FOUCAULT, 1980, p.131).

Assim, as trabalhadoras rurais perceberam os discursos daquela época, analisaram-no e a passividade do grupo se converteu em atividade coletiva, gestual e vocal, materializando os discursos em ações e atraindo uma quantidade cada vez maior de integrantes ao Movimento. "Precisávamos desenvolver um novo jeito de pensar nossas vidas, de mulheres rurais, nosso trabalho, nosso corpo, nossa alimentação" (MF1).

As fundadoras do Movimento tinham como ponto de partida de suas falas, os meios que valorizavam o compromisso com o desenvolvimento e fortalecimento das mulheres pela participação social, política, sindical e partidária, em busca da igualdade de direitos e oportunidades. Esse compromisso é demonstrado no depoimento, a seguir, extraído do relatório do segundo Encontro do Movimento, em 1985: "Vamos dar as mãos a cada hora, descobrir as raízes desse motivo que nos exclui da sociedade em que nós estamos, quando vemos que é só o homem é que quer ter participação ativa, massiva na sociedade (...)" (MF2).

Importa destacar que o Movimento produziu imagens, atividades corporais e oficinas educacionais que trabalhavam o gesto, as expressões artísticas e as contribuições dos sujeitos envolvidos. Essas atividades eram integradas aos encontros anuais, porque as trabalhadoras não tinham o hábito da leitura e da escrita, fruto da restrição, e mesmo da falta de acesso aos estudos. Por essa razão, o início do movimento exigiu das suas fundadoras, um trabalho de corpo a corpo, isto é, para se chegar ao primeiro encontro foi preciso um "porta a porta", conversas com as mulheres sobre a intenção do movimento.

As fundadoras, assim, assumiram o papel de sujeitos do discurso, provocando questionamentos nas falas e atitudes dos demais sujeitos e instituições daquela época. "A Igreja não nos dava o direito de expressar nada. No sindicato, as mulheres não tinham o direito de participar nem de ser sócia" (Entrevistada MF3). Para Foucault (2005), este tipo de abordagem é o que valida a postura do sujeito fundante, que tem como papel, animar diretamente, com suas intenções, as formas vazias da língua. Uma conduta de quem está proferindo o discurso:

É ele que atravessando a espessura ou a inércia das coisas vazias, reaprende, na intuição, o sentido que aí se encontra depositado; é ele igualmente que, para além do tempo, funda horizontes de significações que a história não terá senão de explicar em seguida, e onde as proposições, as ciências, os conjuntos dedutivos encontrarão, afinal, seu fundamento (FOUCAULT, 2005, p. 47).

Quanto às lideranças do MMTR - Sertão Central - PE, ficou constatado que o trabalho inicial das fundadoras possibilitou a participação de várias outras agricultoras, ampliando o grupo. Aos poucos, as mulheres iam saindo da condição de ouvintes passivas, e começavam a discutir os diversos temas, relatar suas experiências e expressar as dificuldades encontradas naquela época. Desse modo, foram protagonizando seus discursos, o que estimulou a liderança em diversas mulheres.

Elas buscaram para a formulação de seus argumentos, o que se conhece na AD como interdiscurso, ou seja, procuraram substanciar suas argumentações, a 
partir do diálogo com diversas temáticas: saúde, trabalho, renda, gênero, entre outras. "Aprendi muito com o Movimento. Passei a ter acesso a muitos conhecimentos e a trocar informações com outras mulheres, crescendo em conjunto" (Entrevistada ML1).

Assim, entende-se que o que era dito nessa época contribuía para que as líderes do movimento assumissem o comando dos discursos - selecionando, informando e influenciando as agricultoras e os outros sujeitos envolvidos, ao mesmo tempo em que acreditavam, interpretavam e seguiam as mesmas enunciações, comandos e expressões. Era a fala carregada de ação. Na perspectiva defendida por Maingueneau (1997), cada ato de fala é inseparável de uma instituição, aquela que este ato pressupõe pelo simples fato de ser realizado.

Levando em consideração o caráter interativo da linguagem, é possível notar que o MMTR - Sertão Central-PE formou líderes que legitimaram os seus discursos, reunindo também as contribuições das agricultoras, expressas em movimentos corporais e artísticos. "A língua comporta a título irredutível, escreve um catálogo completo de relações inter-humanas, toda uma coleção de papéis que o locutor pode escolher para si e impor ao destinatário" (MAINGUENEAU, 1997, p.31).

Analisar os caminhos de mobilização, engajamento e organização dessas trabalhadoras rurais do sertão pernambucano, de um tempo-histórico determinado e com relações de poder desiguais, permitiu considerar que o movimento aliado a uma estratégia de comunicação diferenciada e voltada para a realidade dos movimentos sociais, propiciou uma maior atenção e mobilidade dessas mulheres. O movimento insistia na emersão dos temas e estimulavam a participação das mulheres rurais, e, então, as agricultoras passaram a ter acesso, a apreender as informações e consequentemente passaram a participar dos debates e a (re)construírem seus posicionamentos e expressarem suas vontades. "O MMTR me permitiu ser livre para sonhar, andar, falar o que penso e ajudar outras mulheres que são sofredoras por não conhecer o direito de ser mulher" (Entrevistada ML2).

Na trajetória do MMTR - Sertão Central-PE, a criação do programa de rádio aliada ao novo movimento social, que nascia e crescia no meio rural, foi importante para a transmissão dos discursos construídos coletivamente e comunicados pelas mulheres agricultoras. Por meio da participação ativa dessas agricultoras, esse processo implicou novas posturas, tais como: compreender e se indignar com a exclusão das mulheres nos processos de decisão, se comprometer com o movimento na perspectiva de criador de mudanças, ao mesmo tempo em que ressignificavam seus códigos e formas de discurso. Esse envolvimento do sujeito com a comunicação é um processo de participação popular que valoriza a democracia e a cidadania, como afirmou a entrevistada: "(...) eu tinha minha realidade de saber que mulher também era liberta, mas hoje estou sabendo que a mulher pode trabalhar na libertação de si e dos outros" (ML3).

A criação e organização do Movimento, trouxe ao espaço público discussões, até então, vistas como inferiorizadas e interpretadas negativamente pela sociedade, influenciando o comportamento dos trabalhadores e trabalhadoras rurais, justamente porque ampliou a participação das mulheres nas tomadas de decisão.

Elas construíram novos discursos, questionamentos às falas da sociedade patriarcal e se posicionaram diante das diversas situações conflituosas ao longo de mais de 30 anos de organização, influenciando diretamente no desenvolvimento das comunidades rurais.

Essa convergência de ações e luta por interesses comuns pode ser entendida, ao considerar o conceito de Desenvolvimento Local, que surgiu na década de 1980, e se manifestou como uma nova agenda propositiva, emergindo na tentativa de atender às crescentes demandas sociais por reconhecimento e 
valorização do local e promover ações que melhorassem as condições de vida dos sujeitos sociais envolvidos. Nessa perspectiva, a organização e mobilização da sociedade local são consideradas fatores inovadores e importantes para o desenvolvimento local (JESUS, 2009).

A análise da categoria relativa às jovens agricultoras que aderiram ao MMTR - Sertão Central - PE mostra que elas contaram com um espaço já consolidado e ampliado de discussões e debates. Nasceram e cresceram, acompanhando suas mães e avós, aos encontros e percebendo a ocupação das trabalhadoras rurais à frente de sindicatos, associações e outras entidades. Seus discursos têm fortalecido e remodelado o Movimento e estimulado ainda mais seu engajamento em instâncias estaduais, federais e internacionais, como é possível observar no depoimento dessa entrevistada: "Conscientizar as mulheres, que não basta ser mãe e esposa. Também ser algo mais, conhecer e saber exigir seus direitos" (JM1).

As falas passaram a ser reescritas e reinventadas, e com espaços mais ampliados de divulgação e visibilidade como em plenárias, palestras junto a entidades parceiras, instituições de ensino, entrevistas, artigos e participação em pesquisas cientificas. As jovens mulheres continuaram convidando as trabalhadoras a lutarem por seus direitos e a ocuparem os espaços que lhes cabe na sociedade. Apesar de terem conquistado um maior reconhecimento, elas ainda encontram desafios em questões antigas que atravessaram o tempo, como a violência contra a mulher, a divisão desigual do trabalho, a isonomia salarial, entre outras.

As meninas e os meninos que nasceram dentro do Movimento, entendem a importância de as mulheres terem voz ativa nas questões que influenciam suas vidas. Essas crianças passaram a contar, na última década, entre 2005-2015, com acesso à escola, a universidade e contribuíram com mobilizações, articulações e reivindicações de uma vida mais justa e igualitária no campo, redefinindo assim as relações sociais no meio rural. "As mulheres têm mais liberdade que antes, pois com as nossas conquistas formamos associações, bancos de sementes, projetos de banheiros e fossas. Tudo isso que conseguimos foram nossas conquistas" (JM2 depoimento extraído do relatório do encontro do Movimento, em 2009).

Essas jovens congregaram aos novos discursos elementos essenciais que valorizaram o saber local, aliado às principais necessidades das mulheres da zona rural, levando em consideração suas crenças e experiências de vida, conseguindo criar novos códigos e posturas, ao mesmo tempo em que produziram e contribuíram com o surgimento de argumentos adequados aos diferentes contextos de comunicação. Tiveram como potencializador de suas mensagens, o programa de rádio, que durante toda a trajetória do grupo, atingiu mais de 57 cidades em todo o estado de Pernambuco, e somente, na região do Sertão Central envolveu nove municípios.

Para Foucault (1997, p.49):

O discurso nada mais é do que a reverberação de uma verdade nascendo diante de seus próprios olhos; e, quando tudo pode, enfim, tomar forma de discurso, quando tudo pode ser dito e o discurso pode ser dito a propósito de tudo, isso se dá porque todas as coisas, tendo manifestado e intercambiado seu sentido, podem voltar à interioridade silenciosa da consciência de si.

Temas importantes como trabalho e renda, educação no campo, qualidade de vida, participação e democracia passaram a fazer parte das pautas de 
reivindicações das trabalhadoras rurais. O relato, extraído do documento da FETAPE, em 2016, revela esta nova fase do Movimento: "Não só o Brasil, mas outros países têm o desafio da sucessão rural. A gente espera que as pautas fiquem bem definidas para que possamos caminhar de acordo com que os jovens estão propondo" (JM3).

Os discursos dos sujeitos investigados são compreendidos como os efeitos de sentido que surgem na relação entre interlocutores, considerando estes como sujeitos situados no contexto sócio histórico de uma comunidade, num tempo e espaço concretos e que deixam transparecer suas ideologias nas suas falas e expressões. Pêcheux (1984) defende que o discurso se constitui na relação com os discursos anteriores, ou seja, no interior de um discurso há elementos vindos de outros lugares, outros discursos, e assim, reconhece que a heterogeneidade é constitutiva do discurso.

A partir das diversas atividades implementadas pelo Movimento (criação de imagens, atividades corporais e as diversas oficinas educacionais), além da busca pela educação formal (desenvolvimento do hábito da leitura e da escrita), as agricultoras passaram a melhor transitar por suas comunidades identificando nessas potenciais de desenvolvimento, como arborização, construção de cisternas para captação da água, divulgação do artesanato local e comercialização dos produtos agrícolas. Importa esclarecer que as agricultoras, também, se utilizaram de meios de comunicação como o rádio para informação das atividades do Movimento e divulgação da produção local.

É exatamente neste sentido de conexão das variadas formas de comunicação que as agricultoras se desenvolveram, ora para se expressar, congregar e interagir - fortalecendo seus discursos - ora para trocar ações e reunir ideais, pautados em afinidades e atos de confiança, cooperação e reciprocidade. Nesse sentido, foram criadas, ao longo de toda a trajetória do Movimento, redes associativas, necessárias para a promoção do desenvolvimento da região, contribuindo para a produtividade e o bem-estar das comunidades rurais. $O$ Movimento esteve, assim, baseado nos objetivos reais de promoção de melhoria da qualidade de vida das pessoas, proporcionando o incremento dos níveis de autoconfiança e organização.

Assim, a influência exercida pela comunicação sobre as mulheres agricultoras foi importante, promovendo um melhor entrosamento e comprometimento com o Movimento e repercutiu no modo de ver, sentir e viver. Trata-se de um discurso construído coletivamente, por meio da participação ativa das mulheres, mediante o uso de táticas facilitadoras do envolvimento pessoal e da auto emancipação (PERUZZO, 2010, p.95).

Quanto aos homens agricultores rurais, percebeu-se que, com o passar dos anos os seus discursos, em relação às agricultoras, revelaram que o número de trabalhadores rurais que demonstraram interesse em participar dos encontros foi crescendo gradativamente. Nos primeiros seis anos do MMTR - Sertão Central 1984 a 1990 - apenas os homens que ocupavam cargos de liderança demonstravam valorização e estímulo à participação das mulheres. Na segunda década do Movimento - 1995 a 2005 - eles passaram a participar da abertura e fechamento dos encontros e, depois de 2006, começaram a discutir os temas transversais como AIDS, gênero e sexualidade, expondo suas ideias e ouvindo as opiniões das trabalhadoras rurais, numa importante troca de experiências para o desenvolvimento local e pioneiro no sertão pernambucano.

Dos homens que presenciaram o surgimento do MMTR - Sertão Central PE nas décadas de 1980 e 1990, poucos apoiaram a luta das mulheres e estimulavam a sua participação no Movimento. Alguns deles ocupavam cargos de 
liderança como presidentes de sindicatos ou associações e revelaram em seus discursos, a importância da participação feminina nos espaços públicos. "Só as mulheres reunidas, falta alguma coisa, só os homens, também falta. O ideal é a luta dos dois. Homens e mulheres, trabalhadores e trabalhadoras, juntos" $(\mathrm{H} 1$ Depoimento extraído do relatório do Movimento, em 1985).

Todavia, muitos discursos dos homens, daquela época, explicam o medo diante do crescimento e visibilidade conquistados pelas trabalhadoras rurais, ainda revelando na formação discursiva desses homens, os procedimentos de controle:

\begin{abstract}
Nunca tinha participado de uma reunião como essa, onde a mulher está demonstrando a todo tempo sua força, sua capacidade de realizar alguma coisa. Que ela possa ter o interesse de classe possa ser dona de si mesma, mostrar sua capacidade, isso muitas vezes, deixa o homem com inveja. (H2-Depoimento extraído do relatório do Movimento, em 2009).
\end{abstract}

Foucault (1997) entende que a verdade, organizada e convencionada pelas instituições, é estreitamente ligada à formação de sujeitos, bem como à sua linguagem. Desta forma, o saber é constituído por um conjunto de práticas discursivas, pressupõe relações que se tornam determinantes para as práticas discursivas. Esse saber constitutivo de prática é perceptível no depoimento que se segue: “(...) lamento que não sejam todos os homens do Movimento Sindical que apoiam de verdade a luta das mulheres. Alguns veem como um movimento paralelo. Eu vejo como uma organização que pode contribuir muito na luta conjunta" (H3 Depoimento extraído do relatório do Movimento, em 2009).

Infere-se que alguns desses discursos estão associados ao poder, que se expandiu pela sociedade, assumindo formas de dominação. O poder intervém materialmente, atinge ou constitui indivíduos ideologicamente e penetra em suas atitudes cotidianas.

Nessa perspectiva, e considerando o pensamento de Foucault (1997), o poder mostra a alternância entre uma positividade e uma negatividade que the é atribuída, mantendo a ideia de propriedade e exercício de um único soberano, ou de uma minoria, sobre uma maioria. As relações de poder inserem-se em todos os lugares, em todos os níveis de relação social existentes na sociedade.

A visão do autor de que o poder se encontra nas relações sociais, sob a forma de relações de força, pressupõe a formação de resistência a todo o exercício de poder. E é no pensamento desse estudioso que se encontra a ideia de que o aparecimento dos saberes é permeado pelas relações de poder porque o sujeito é efeito-objeto de relações de poder. Saber e poder implicam-se mutuamente. Não há relação de poder sem a construção do saber e todo saber constitui novas relações de poder. Todo o exercício do poder é também um lugar de formação do saber.

Desta maneira, percebe-se que as agricultoras inverteram a ordem do discurso, e que através do conhecimento adquirido, de todo o processo de mobilização, formação e engajamento da organização social e política tiveram a chance de fomentar novos questionamentos e conquistar novos posicionamentos, que lhes garantiram visibilidade, autonomia e empoderamento.

Depois dos anos 2003, o fato de os homens passarem a participar dos encontros anuais das trabalhadoras rurais, ouvirem suas opiniões, contribuírem com as avaliações e analisarem os temas que o meio rural vivenciava naquela época, proporcionou um novo significado aos discursos desses homens, ressaltando a importância da participação da mulher nos sindicatos, nos trabalhos da roça e nas decisões particulares. Passou a conjugar o poder de afirmação das agricultoras, em 
suas participações também em espaços coletivos, afirmando que era "possível conviver de forma igual", conforme o relatório de 1999, que avaliou o $10^{\circ}$ encontro e que envolveu 105 trabalhadores e trabalhadoras rurais. Naquele momento, alguns homens destacaram em suas falas que foi a primeira oportunidade que tiveram de entender e discutir as situações que envolviam homens e mulheres rurais.

Uma das oficinas trabalhou o corpo, o que representou um momento de reavaliação para os trabalhadores rurais, como descreve esse trabalhador rural: "Antes via o corpo só para trabalhar, botar força. Nesses dias aqui vimos que o corpo é muito mais que isso, é bonito e pode nos dar prazer" (HA1. Depoimento extraído do relatório do Movimento, em 2009).

É possível perceber que os homens professavam discursos de forma diferenciada das falas que os criaram, esses discursos foram transformados através dos caminhos percorridos pelas trabalhadoras rurais dentro do MMTR - Sertão Central - PE, e lhes conferiram visibilidade e reconhecimento como constata o agricultor entrevistado:

\begin{abstract}
Por que é que a maior parte das mulheres humildes mora nas comunidades sem água encanada, sem coleta de lixo, sem saneamento? Porque é que só de um tempo pra cá os programas habitacionais garantiram à mulher financiamento à casa própria e o nome da mulher na escritura da casa? (HA2).
\end{abstract}

Falas como esta, demonstram a preocupação dos homens rurais, em cobrar do poder público uma melhor qualidade de vida para as mulheres e suas famílias, por meio de políticas públicas habitacionais, educacionais, de saúde, etc.

A essa determinação, em ultima instância, Pêcheux (1990) denomina como "função ideológica" ou "condições de produção do discurso". Desta forma, entendese que uma sociedade possui várias formações ideológicas, e a cada uma delas corresponde uma "formação discursiva" que define o que se pode e se deve dizer em determinada época, em determinada sociedade. Desse modo, os processos discursivos estão na fonte da produção dos sentidos e a língua é o lugar material onde se realizam os "efeitos de sentido". Ao mudar a realidade local, trabalhadoras influenciaram trabalhadoras e trabalhadores, para que juntos, mudassem o sentido de seus discursos.

Analisando-se a categoria relativa aos discursos das instituições: sindicatos e outras organizações ficaram evidenciados que a ampliação do debate sobre a posição social das trabalhadoras rurais ganhou força depois de 2006, quando o Movimento já conquistava um maior reconhecimento, junto às instituições nacionais e internacionais. Assim, percebia-se que no MMTR - Sertão Central - PE, as distâncias entre homens e mulheres já estavam mais estreitas e os discursos começavam a ser (re)criados, ao mesmo tempo em que surgiam novos grupos de mobilização, que buscavam dar mais visibilidade às agricultoras, se reunindo e levando as reivindicações às instâncias federais.

A voz das trabalhadoras rurais do MMTR - Sertão Central - PE era uma só e isso resultou em um processo de aprendizagem, que envolveu diversas parcerias ao longo desses mais de 30 anos de articulação, que valorizaram as experiências locais e que conseguiram convergir para o fortalecimento da organização coletiva, numa força propulsora em prol dos direitos das trabalhadoras rurais e do desenvolvimento das suas comunidades. 
esses caminhos eu consigo enxergar, vê-los sem que ninguém me mostre. Graças a todo este esforço vivido em grupo, que para mim sem viver em grupo, comunidades organizadas não há mais conscientização nem igualdade (Entrevista - I1).

A afinidade e o incremento da comunicação dentro do Movimento já influenciavam as comunidades rurais locais e expandia-se em nível nacional. Depois de 2005 , a participação das mulheres nos eventos foi cada vez mais significativa. As trabalhadoras rurais já participavam de diversos eventos, como passeatas, greves, piquetes. O maior deles, é a Marcha das Margaridas, levando propostas de melhoria da qualidade de vida das trabalhadoras rurais às instâncias federais. Percebe-se que na marcha, os discursos estão reafirmados, rediscutidos e reagrupados. As Margaridas construíram um documento com reivindicações representando o desejo de mais de 700 mil trabalhadoras rurais no Brasil, considerando apenas o ano de 2015. "E como é difícil romper com tais desafios impostos às mulheres. Um tom em defesa da democracia, que diz "não" ao retrocesso dos direitos das trabalhadoras e trabalhadores, ao conservadorismo dos governantes e ao preconceito nas suas mais diversas formas" (I2 Declaração extraída do relatório do Movimento, 2006).

As mudanças provocadas pela trajetória do MMTR - Sertão Central - PE apontaram para a necessidade de uma luta para desenvolver uma nova linguagem como elemento chave na construção de uma sociedade mais igualitária, e talvez, promover um entendimento melhor do que está inserido nesse processo de "ressignificação".

Ao longo desses mais de 30 anos de trajetória, as trabalhadoras rurais contabilizaram diversas conquistas como o reconhecimento profissional, a materialização da documentação que proporcionou a inclusão social e o acesso aos outros direitos previdenciários e trabalhistas; assim como o desenvolvimento de campanhas importantes como o enfrentamento da violência contra a mulher. Em nível local, lutaram pelo direito de serem assentadas, de ter crédito rural, incluindo nesse grupo, as mulheres viúvas e solteiras. Participam ainda de feiras livres e passaram a comercializar o produto final produzido na roça.

\section{CONSIDERAÇÕES FINAIS}

Analisar os caminhos de mobilização, engajamento e organização do Movimento de Mulheres Trabalhadoras Rurais do Sertão Central de Pernambuco MMTR - Sertão Central - PE foi uma experiência rica de significados, de interpretações e de estudos aprofundados sobre os sujeitos, sobre sua linguagem, suas falas, símbolos comunicacionais e as variadas formas utilizadas de expressão. A participação dessas trabalhadoras rurais, no movimento social, pioneiro no Brasil, proporcionou diversas conquistas durante mais de 30 anos de atuação, ao mesmo tempo em que iniciou um processo de transformação e "ressignificação" de valores no meio rural.

Nesta trajetória, levou-se em conta que o discurso foi o elo inicial de articulação do trabalho desenvolvido pelas fundadoras do Movimento, influenciando com suas palavras e abordagens às outras mulheres a participar da luta pela igualdade nas relações sociais. A linguagem desenvolvida nesse recorte temporal foi percebida como interação em um modo de vida, aproximando as mulheres que até então viviam isoladas e silenciadas. Uma troca que não foi revelada de forma neutra, nem natural, contando com a interferência e insistência de líderes e fundadoras do Movimento, que se moveram diante da não participação das agricultoras nos sindicatos e nos diversos espaços da sociedade. Essas mulheres 
tiveram a chance de entender os discursos vigentes, analisá-los, discuti-los e refazêlos; e passaram a influenciar a formação de outras líderes e jovens trabalhadoras rurais que já contribuíram com o Movimento, de forma diferenciada diante das situações que envolviam o universo rural.

Procurou-se identificar as estratégias de comunicação utilizadas pelo Movimento e compreender as contribuições que a organização de trabalhadoras rurais proporcionou à vida das mulheres agricultoras e ao desenvolvimento local. Assim, percebeu-se que em poucos anos, as agricultoras passaram a entender melhor os discursos da sociedade da época, descobriram que poderiam ir de encontro ao que era dito, se reuniram, se manifestaram em grupo e chamaram a atenção para novos discursos e posicionamentos. Conquistaram e ganharam o direito a ter voz. Falaram, influenciaram, formaram líderes e criaram programas de rádio pautado em reivindicações legítimas, influenciando a região sertaneja, 0 estado e o país.

Com essa articulação, as trabalhadoras rurais conquistaram o reconhecimento profissional e passaram a ser identificadas como trabalhadoras rurais. Outros avanços foram contabilizados: passaram a participar das reuniões sindicais e a opinar, foram convidadas a exercer cargos dentro dos sindicatos, e provaram seu valor e competência. Enfrentaram diversos preconceitos e discriminações nestes espaços de poder, mas buscaram desenvolver trabalhos que beneficiaram homens e mulheres do campo, com o desenvolvimento de campanhas educativas para levar informação aos trabalhadores rurais, e hoje, segundo dados da pesquisa, as mulheres são maioria e contribuem com o sindicato regularmente. Inclusive, no Polo Sertão Central, a maior parte dos sindicatos, é liderada por mulheres e têm a maioria de diretoras, também, no setor financeiro. Um dado colhido na pesquisa, é que o Sindicato dos Trabalhadores Rurais da cidade de Triunfo, conta com $90 \%$ de mulheres, tratando as questões rurais com igualdade e respeito, o que tem provocado excelentes resultados no que se refere à vivência dos direitos de homens e mulheres do campo, como orientação jurídica para o acesso aos direitos previdenciários e ao crédito rural, assim como instruções sobre o processo de comercialização dos produtos em feiras e espaços comunitários.

Desta forma, conclui-se que a participação das trabalhadoras rurais sempre foi importante e a luta por sua valorização - como trabalhadora rural, mãe e esposa provocou ações importantes e que começaram a dar frutos. A participação dessas mulheres em outros espaços sociais - como sindicatos, conselhos, associações, federações, confederações - proporcionam a elas novos lugares de fala, o que revela os repertórios construídos coletivamente. Acumulam assim capital intelectual, cultural, político e social para atuarem nestes espaços e representarem 0 Movimento.

O Movimento ainda tem muitos desafios a enfrentar, assim como questões que não foram resolvidas ao longo desses anos de atuação, mas a marcha por desenvolvimento sustentável com democracia e justiça continua. As trabalhadoras rurais acreditam em uma Reforma Agrária que reconheça os territórios dos povos indígenas e das comunidades tradicionais, assim como uma justa repartição da terra que ainda está concentrada nas mãos de latifundiários. Elas buscam alternativas para a convivência com os efeitos da seca, e com isso, reafirmam seus discursos e intensificam os trabalhos de base, levando informação durante as reuniões e participando de atividades em prol da melhoria de vida no campo.

\section{REFERÊNCIAS}

ABREU E LIMA, M. As mulheres no sindicalismo rural. Recife: UFPE, 2012. 
ALMEIDA, V. Lutando e lutando. Recife: Instituto Papai. 2013.

Ser mulher no mundo de homens. Serra Talhada: MMTR-NETHRESHOLD FOUNDATION, 1995. Florianópolis: Editora da UFSC, 1999.

; PEIXOTO, L.I. Uma história muito linda: Rede de Mulheres Rurais da América Latina e Caribe. Recife, 2007.

ALMEIDA, V.; PARISIUS, C. Ser mulher num mundo de homens: Vanete Almeida conta sua vida a Cornelia Parisius. Serra Talhada: Universal, DED/SACTES, MMTR/NE, 1995.

FOUCAULT, M. A ordem do discurso. São Paulo: Edições Loyola, 2005.

JARA, C. colaboração de Maria Verônica Morais Souto. As dimensões intangíveis do desenvolvimento sustentável. Brasília: Instituto Ibero-americano para o Desenvolvimento da Agricultura- IICA, 2000, 352 p.

JESUS, P.; TIRIBA, L. Cooperação. In: CATTANI, A. D. (org.) A outra economia. Porto Alegre: Veraz Editores, 2003.

MAINGUENEAU, D. Análise do discurso: uma entrevista com Dominique Maingueneau. Revista Virtual de Estudos de Linguagem, v.4, n.6, 2006. Tradução de Gabriel de Ávila Othero.

MELUCCI, A. Movimentos sociais, renovação cultural e o papel do conhecimento. Revista Novos Estudos, n. 40, p.152-166, nov., 1994.

MOVIMENTO DAS MULHERES TRABALHADORAS RURAIS DO SERTÃO CENTRAL DE PERNAMBUCO. Uma história de mulheres. Serra Talhada, 1994.

Proposta para aumentar a participação de nós mulheres, trabalhadoras rurais, no nosso movimento sindical. Serra Talhada, 1985.

Relatório do I Encontro de Mulheres Trabalhadoras Rurais do Sertão Central (dezembro de 1984). Serra Talhada, 1985 a 2000.

ORLANDI, E. Análise de Discurso: princípios e procedimentos, 8aㅗ ed. Campinas: Pontes, 2009. 100p.

PÊCHEUX, M. I. Delimitações, inversões, deslocamentos. Cadernos de Estudos Linguísticos, n.19. Campinas: Unicamp. 1990.

PERUZZO, C. Comunicação nos movimentos populares: a participação na construção da cidadania. 3. ed. São Paulo: Vozes, 2004.

POLO SINDICAL SERTÃO CENTRAL. Mulher excluída do programa de emergência. Serra Talhada, 1983.

SOUZA, G.; LIMA, F.; VARGAS, L. et al. A extensão rural e a perspectiva de gênero na agricultura familiar: a atuação do IPA junto à Associação Municipal Flor do 
Campo. Extensão Rural, Santa Maria, v.23, n.2, abr./jun. 2016. Disponível em: <https://periodicos.ufsm.br/extensaorural/article/view/16985/pdf_1>. Acesso em: 29 maio 2017. 